\title{
Yield, transpiration efficiency, and water-use variations and their interrelationships in the sorghum reference collection
}

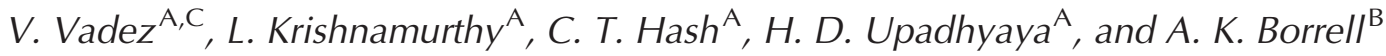 \\ A ICRISAT, Patancheru 502324, Andhra Pradesh, India. \\ ${ }^{B}$ The University of Queensland, Queensland Alliance for Agriculture and Food Innovation, \\ Hermitage Research Station, Warwick, Qld 4370, Australia. \\ ${ }^{\mathrm{C}}$ Corresponding author. Email: v.vadez@cgiar.org
}

\begin{abstract}
Sorghum is well adapted to water-limited conditions, but the traits responsible for this enhanced adaptation under drought conditions remain unclear. In this study, yield, transpiration efficiency (TE) and water extraction were assessed in 149 germplasm entries from the sorghum reference set (plus three control cultivars) using a lysimetric system under terminal water stress and fully irrigated conditions outdoors. A 10-fold range for grain yield and harvest index (HI), 2-fold range for TE and a 1.25-fold variation for water extraction were observed under terminal water stress conditions. Transpiration efficiency and water extraction under water stress related poorly to that under fully irrigated conditions, reflecting a large genotype-by-water treatment interaction. Under drought stress, total water extraction varied by $3 \mathrm{~L} \mathrm{plant}^{-1}$ among germplasm. Entries from the Durra race had highest water extraction capacity, whereas Caudatum-Bicolor and Caudatum-Durra intermediate races had poor water extraction. Durra, Caudatum and Caudatum-Guinea races had highest TE, whereas the Guinea race had the lowest. Although yield was closely related to HI, at any level of HI there were substantial yield differences that remained unexplained, and these residual yield variations were closely related to TE $\left(R^{2}=0.60\right)$. Similarly, substantial yield variations that were still not explained by HI or TE were closely related to the total water extracted under water stress $\left(R^{2}=0.35\right)$. A multilinear regression analysis confirmed these results and showed the importance of water extraction during grain filling. Therefore, next to HI, the yield differences under terminal drought in sorghum were driven by $\mathrm{TE}$, and then next by water extraction. The large genetic variation for TE and water extraction offer great breeding opportunities and in particular, highlight the Durra race as a critical source of variation.
\end{abstract}

Additional keywords: germplasm reference set, pre-anthesis water use, roots, water uptake profile.

\section{Introduction}

Water deficit is the most important abiotic stress and significantly limits crop production globally, particularly in the Semiarid Tropics. There are different 'patterns' of water stresses depending on the timing, the intensity, and the duration of drought stress (Serraj et al. 2005). In the Semiarid Tropics, where the length of the cropping period is limited, sorghum often faces a terminal drought, caused by the cessation of rain towards the end of the rainy season. This is particularly the case for post-rainy ( $r a b i)$ sorghum in India, which is sown at the end of the rainy season to take advantage of the moisture accumulated in the soil profile. Successful crops under terminal drought are those having increased water availability and accessibility during grain filling (Vadez et al. 2007a). Possible options for increasing water availability post-anthesis are to: (i) manage the soil moisture profile in a way that leaves water available for grain filling, including strategies to minimise water use before anthesis (Kholová et al. 2010a, 2010b) or strategies to enhance transpiration efficiency (TE); (ii) develop a deeper and/or more profuse rooting system to access extra water from the soil profile.
Having higher TE (in $\mathrm{g}$ biomass $\mathrm{kg}^{-1}$ water transpired) could contribute to a slower rate of soil moisture depletion. Genotypic differences for TE have been reported in sorghum under well watered conditions (Hammer et al. 1997; Xin et al. 2009). Few studies have looked at TE under both fully irrigated and water stress conditions (Donatelli et al. 1992; Balota et al. 2008), with only a limited range of germplasm being assessed. Also, except Balota et al. (2008), TE has been measured over relatively limited periods of time. So it is therefore important to assess genetic variation for $\mathrm{TE}$ over an entire crop cycle and to determine whether there are large genotype-by-water regime interactions for TE. We used this approach to assess a large and diverse set of germplasm lines from the sorghum reference set (Ramu et al., unpubl. data).

Rooting traits have been reported as potentially important for drought adaptation in sorghum (Bhan et al. 1973; Mayaki et al. 1976; Blum et al. 1977; Jordan et al. 1979) based on studies involving a limited number of genotypes. In one study, the roots of a drought-tolerant sorghum line grew at least $40-\mathrm{cm}$ deeper than a drought-sensitive one (Salih et al. 1999). Yet, root measurements are time consuming and prone to error 
(Vadez et al. 2007a), and the range of genotypic variation for the capacity to extract water from a soil profile remains unknown. This is critical information to gather since recent simulation and experimental work in wheat shows that each millimetre of water extraction during the grain-filling period contributes to an additional $55 \mathrm{~kg} \mathrm{ha}^{-1}$ grain yield (Manschadi et al. 2006) and $59 \mathrm{~kg} \mathrm{ha}^{-1}$ grain yield (Kirkegaard et al. 2007), respectively. It was also shown that the total water extraction did not differ between the tolerant and the sensitive wheat genotype, but the tolerant line used less water before anthesis and more after anthesis than the sensitive line (Manschadi et al. 2006). Here, similar hypotheses are developed in sorghum to assess differences in the total water extraction and the proportion of water being used during the post-anthesis period to service grain filling (Hammer 2006).

Passioura's equation (Passioura 1977) $(\mathrm{Y}=\mathrm{WU} \times \mathrm{TE} \times \mathrm{HI}$, with Y, WU, TE, and HI standing for yield, water used, transpiration efficiency and harvest index) has been widely used to guide the search for traits contributing to drought adaptation. However, since there was no method to evaluate all components on the same plants with an equal degree of precision, the use of that equation was generally limited to only single components, regardless of the relative importance of other components. For example, the past 20 years of drought research in groundnut has focussed on water-use efficiency (Hubick et al. 1986; Wright et al. 1994; Udayakumar et al. 1998; Nageswara Rao et al. 2001; Krishnamurthy et al. 2007), often relying on surrogates to estimate trait value. Similarly, rooting traits have been used as surrogates for water extraction (the WU component) (reviewed in Vadez et al. 2007a). Whether high TE relates to low water use (Blum 2005) or not (Peng and Krieg 1992) is still a matter of debate. Also, it is possible that one of the components of the equation may have, under specific conditions, a greater bearing on yield, thereby obscuring the true contribution of the other components to yield. Here, a method is used (Vadez et al. 2008; Ratnakumar et al. 2009) to precisely assess all components of Passioura's equation on the same plant and test their relationships using a large set of germplasm.

Sorghum is among the most adapted crops to dryland farming. Yet there is considerable genetic diversity available for adaptation to water deficit (Crasta et al. 1999; Harris et al. 2006). Recently, a mini core collection of 242 accessions of sorghum germplasm lines representing global diversity in core and entire collections has been developed using data on 21 phenotypic traits (Upadhyaya et al. 2009). More recently, a reference set collection based on data from 41 simple sequence repeat markers consisting of 384 entries has been developed (Ramu et al., unpubl. data). We assess variation in the traits described above in a subset of the reference set of sorghum which was chosen to limit variation in their time to flowering.

The overall objective of the present study was to assess variation in the sorghum reference collection for traits related to plant water use and hypothesised to be closely related to crop adaptation under terminal drought. We specifically assessed: (i) the genotypic differences in water extraction and the pattern of water use before and after anthesis; (ii) the genotypic variation in TE; (iii) the range of water regime-by-genotype interaction for these traits; (iv) the contribution of these traits to grain yield under terminal drought, and (v) possible association between specific sorghum races and values of the traits assessed.

\section{Materials and methods}

\section{Soil and growth conditions of the lysimeters}

Plants were grown in lysimeters, i.e. PVC tubes of $25-\mathrm{cm}$ diameter and 2.0-m length, filled with Alfisol in outdoor conditions, with possibility to cover them with a shelter in case of rain. A PVC end plate was placed on top of four screws at the bottom of the cylinders, $3 \mathrm{~cm}$ from the very bottom, to prevent the soil from seeping through. The endplate did not fit the cylinder tightly and allowed water drainage, although drainage was prevented when lysimeter weighing started (see below). Tubes were filled with Alfisol collected from the ICRISAT farm and sieved to particles smaller than $1 \mathrm{~cm}$. This allowed the bulk density of the soil profile to be set at $\sim 1.35 \mathrm{~g} \mathrm{~cm}^{-3}$, a standard value for Alfisols. Cylinders were filled with soil in three increments of $40 \mathrm{~kg}$ of dry soil. After addition of each $40-\mathrm{kg}$ increment, the soil level in several cylinders was checked to ensure they were similar in all tubes. Then each $40 \mathrm{~kg}$ of soil added was watered. A previous assessment of the water needed to fill the profile before drainage determined that the soil water-holding capacity of the Alfisol was $\sim 20 \%$. Therefore, $8 \mathrm{~L}$ of water were added to each $40-\mathrm{kg}$ increment of soil. After adding/watering $40 \mathrm{~kg}$ of soil three times, an additional $15 \mathrm{~kg}$ of dry soil was added to each cylinder and watered with $3 \mathrm{~L}$. At that stage, the cylinders were almost filled to the desired level, i.e. $\sim 5 \mathrm{~cm}$ from the top. A top-up using dry soil was done to ensure that all cylinders were filled to the same level. This top-up varied between $\sim 1$ and $2 \mathrm{~kg}$, i.e. less than $1-2 \%$ variation across cylinders. Hence, all the cylinders had a similar bulk density close to $1.35 \mathrm{~g} \mathrm{~cm}^{-3}$. All cylinders at field capacity weighed between 163 and $165 \mathrm{~kg}$.

The soil in the lysimeters had been fertilised with DAP and muriate of potash, both at a rate of $200 \mathrm{mg} \mathrm{kg}^{-1}$ soil. It was also complemented with sieved and sterilised farm manure at a rate of $2: 50$ to prevent micro-nutrient deficiency. Before growing the sorghum crop, the lysimeters were used for a crop of finger millet and foxtail millet, planted sequentially. The foxtail millet crop had received a urea top-dressing of $3 \mathrm{~g} \mathrm{plant}^{-1}$. At the end of this crop, only the main root stock from the plants was removed from the top layer of soil by softening the top soil with water and pulling. The soil was then tilled superficially with sickles and limited Alfisol top-up was added so that the surface level was $\sim 5 \mathrm{~cm}$ below the lysimeter brim. This created a soil profile that was undisturbed from previous cropping, except for minimum tillage of the surface. The lysimeters were then watered to field capacity, based on their expected weight, and the sorghum crop was planted on a full profile. The crop was top-dressed with $3 \mathrm{~g}$ urea plant ${ }^{-1}$ at 4 weeks after sowing.

\section{Space arrangement of the lysimeters and weighing}

The top of the cylinders was equipped with a metal collar and rings that allowed them to be lifted. Weighing of the cylinders was done by lifting the cylinders with a block-chained pulley, and an S-type load cell (Mettler-Toledo, Geneva, Switzerland) was inserted between the rings of the cylinder and the pulley. 
The scale (200-kg capacity) allowed repeated-measurements with an accuracy of $20 \mathrm{~g}$ on each weighing. The lysimeters were separated from one another by a distance of $\sim 5 \mathrm{~cm}$. Thus the sorghum crop was planted at a density of $\sim 11$ plants $\mathrm{m}^{-2}$, a plant population similar to typical field plantings at ICRISAT (row-to-row distance of $60 \mathrm{~cm}$ and plant-to-plant spacing of $15 \mathrm{~cm}$ ). This allowed us to accurately assess the water extraction pattern of a crop cultivated in conditions similar to the field. The tubes were arranged in four trenches of 2-m depth and $1.75-\mathrm{m}$ width. Each trench was separated by a 20-cm concrete wall. Possible border effects were expected on the south side of the trenches (these were oriented east-west) and those effects were curbed by bordering the trench with two rows of plants on the south side of the trenches.

\section{Treatments used and traits assessed}

The DS (drought stress) treatment received no water from 28 DAS until maturity, except for $2 \mathrm{~L}$ that were added to all cylinders at 73 DAS (beginning of grain filling), whereas the WW (well-watered) treatment was irrigated regularly (see below). Four seeds were planted in each cylinder on 20 October 2008 during the rabi sorghum season. Plants were thinned to two seedlings per cylinder at 14 days after sowing (DAS) and then to one plant per cylinder at 21 DAS. Disturbance to remaining plant was avoided by clipping the thinned plant below the collar. All plants were fully irrigated until 28 DAS. This involved cylinders receiving $500 \mathrm{~mL}$ twice a week for the first 2 weeks after sowing, and then on alternate days until 28 DAS. At 28 DAS, the cylinders were covered with a 2-cm layer of low density polyethylene beads to prevent soil evaporation. Preliminary testing indicated that the beads prevented more than $90 \%$ of the soil evaporation, so that differences in mass primarily reflected plant transpiration (data not shown). Biomass increase between weighing was negligible compared with plant water use. Weighing of the cylinders was done at 30 DAS for the first time and then subsequently every 2 weeks. This gave a total of five weights until harvest for the DS plants and six weights for the WW plants. The first weighing at 30 DAS gave the field capacity weight of each cylinder. The cylinders were distributed in four trenches and the weighing of one trench per day was done. The same sequence of weighing was used for each trench so that the time intervals between weighing were the same in all cylinders.

To keep the WW plants sufficiently wet for optimum growth and to avoid water drainage after irrigation, the WW plants were watered when the cylinder weight, at the time of weighing, had fallen below $2 \mathrm{~L}$ from the weight at field capacity. This prevented drainage at the bottom. The watering was done every week. The week that plants were not weighted, the water addition of the previous week was used for watering the WW plants.

Flowering time (days) was recorded on a plant basis. Transpiration was calculated at $\sim 2$-weekly intervals between 31 DAS (the time at which weighing started) and maturity. Daily transpiration values were calculated for each plant by dividing the transpiration for each time interval between weighing by the number of days in each interval. Pre-anthesis transpiration was the sum of the daily transpiration values until anthesis, plus water used in the first 28 DAS, which was estimated to be $1.5 \mathrm{~L}$ for all genotypes. This was based on dry biomass estimates of $15 \mathrm{~g}$ at $28 \mathrm{DAS}$ and on the assumption of a TE of $10 \mathrm{~g} \mathrm{~kg}^{-1}$ water transpired at such an early stage (our unpublished observations). The post-anthesis water use was the sum of the daily transpiration values from anthesis until maturity. Harvest was done over a period of 4 days. Leaf, stem (including sheath) and panicle masses were recorded after drying for 3 days in a forced-air oven set at $70^{\circ} \mathrm{C}$. Panicles were then subsequently threshed to determine grain yield. The HI was calculated as the ratio of grain yield divided by the total aboveground biomass (the aggregated mass of stems, leaves, and panicles). Transpiration efficiency was calculated as the ratio of the total aboveground biomass divided by the sum of transpiration values between $30 \mathrm{DAS}$ and maturity. The initial biomass at the time of initiating the transpiration measurements was not taken into account, assuming that biomass differences between genotypes at that stage were negligible. This would have led to a slight overestimation of TE.

\section{Plant material}

The flowering time of 384 lines belonging to the sorghum reference set had been determined under field conditions in 2008-09 (H. D. Upadhayaya, pers. comm.). Based on these data, 149 reference set entries and three control cultivars, IS 2205, IS 18758, and IS 33844, varying in flowering time between 70 and 85 DAS, were selected. IS 2205 is a Durra-Bicolor landrace resistant to shoot fly and stem borer. IS 18758 is a Guinea-Caudatum landrace, released as E 35-1 in Burkina Faso in 1983 and as Gambella 1107 in Burundi in 1990. IS 33844 is a Durra landrace released in India as Parbhani Moti in 2002. The 149 reference set lines represented 30 out of 44 countries in the entire reference set. Race-wise composition was Caudatum (31), Durra (18), Bicolor (17 accessions), Guinea (14), Kafir (6), Guinea-Caudatum (24), Caudatum-Bicolor (14), Durra-Caudatum (13), Durra-Bicolor (3), Kafir-Bicolor (1), and Kafir-Caudatum (1). An accession each of aethiopicuum and virgatum, two accessions of drummondii, and three of verticilliflorum were also part of the 149 reference set material.

In addition to the DS and WW sets of plants used above, a third set of plants was sown at the same time in an area adjacent to the trenches. Plants were grown in $25-\mathrm{cm}$ pots filled with $11 \mathrm{~kg}$ of the same Alfisol. Previous experiments in sorghum using these pots showed no signs of growth restriction due to pot size up to anthesis. The same planting procedures were used and plants were kept well watered until harvest. This set was harvested at flowering and its purpose was to evaluate leaf area and tillering characteristics of the different genotypes at that stage.

\section{Data analysis}

The experiment design was an Alpha lattice with 19 blocks of eight entries within each block. There were three replications and two water regimes (WW and DS). The Residual Maximum Likelihood method of GENSTAT was used to obtain the unbiased estimate of the variance components and the best linear unbiased predictions for the different parameters measured within each treatment, considering genotypes as random and replications as fixed effects. The significance of the genetic variability among accessions within treatment was assessed from the standard 
error of the estimate of genetic variance $\sigma_{\mathrm{g}}^{2}$. Analysis was also performed to assess the effect of genotype, water treatment and genotype-by-water treatment $(\mathrm{G} \times \mathrm{T})$ interaction for the different traits measured. In this case, genotype and $\mathrm{G} \times \mathrm{T}$ were considered as random effects whereas treatment and replication were considered as fixed effects. The significance of genetic variability across treatments or of the $\mathrm{G} \times \mathrm{T}$ interaction effect was assessed in a manner similar to the above. The significance of the fixed effect of the treatment was assessed using the Wald statistic that asymptotically follows a $\chi^{2}$ distribution.

For the multilinear regression analysis, a multilinear model was used in the software STATA (Stata Corp., College Station, TX, USA), where yield was taken as an additive function of HI, $\mathrm{TE}$, total water extraction, water extracted in the post-anthesis period, water extracted in the 45-59 DAS and 59-78 DAS period, days to flowering, and a constant. The same multilinear model was used to assess the residual yield variations not explained by HI (see below), therefore excluding HI from the list of explanatory variables.

\section{Results}

\section{Yield and biomass components}

Grain yield varied significantly between genotypes under DS conditions, ranging from 0.3 to $36.6 \mathrm{~g} \mathrm{plant}^{-1}$ (Fig. 1a). Overall, the mean yield of $20.6 \mathrm{~g} \mathrm{plant}^{-1}$ under DS conditions was $\sim 50 \%$ of the yield mean under WW conditions (42.0), indicating that the stress imposed was neither too severe nor too mild (Table 1). Under WW conditions, grain yield varied from 2.1 to $82.8 \mathrm{~g} \mathrm{plant}^{-1}$. Grain yield under WW and DS conditions were poorly related $\left(R^{2}=0.10\right)$, which also reflected the large $\mathrm{G} \times \mathrm{T}$ interaction for grain yield (Table 1).

Harvest index also varied significantly between genotypes under DS conditions, ranging from 0.05 to 0.52 (Fig. 1b), except for two genotypes that did not produce any grains. The overall mean $\mathrm{HI}$ of 0.27 under DS was only slightly smaller than the mean HI under WW conditions $(0.33)$. The $\mathrm{HI}$ also varied considerably under WW conditions, ranging from 0.21 to
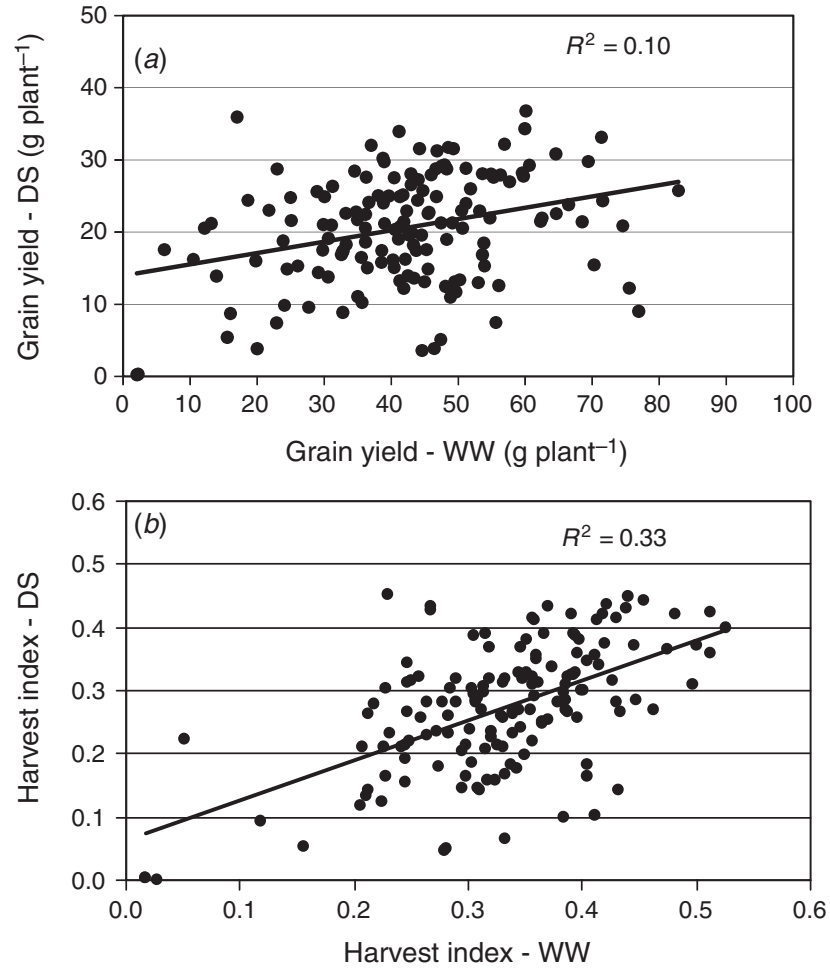

Fig. 1. Relationship between grain yield under terminal water stress (DS, $g$ plant $^{-1}$ ) and grain yield under well watered conditions (WW, g plant ${ }^{-1}$ ) (a), and relationship between harvest index under DS and harvest index under WW $(b)$ in 152 germplasm entries. Data are the mean of three replicated lysimeter-grown plants per genotype.

0.53 , except for five genotypes that had a poor HI lower than 0.15 . Contrary to the grain yield data, the HI under DS conditions was better related to the HI under WW conditions $\left(R^{2}=0.33\right)$ (Fig. 1b), although $\mathrm{HI}$ also displayed a significant $\mathrm{G} \times \mathrm{T}$ interaction (Table 1). The total plant biomass varied largely between entries. Under DS conditions, there was a 2-fold

Table 1. Trial means, range of expected means, genetic variance estimate and standard error of estimate, standard error of differences (s.e.d.) within treatment, and Wald statistics and $F$-probability for genotype effect, treatment effect and genotype-by-treatment $(G \times T)$ interaction related to time to flowering (day), grain dry mass $\left(\mathrm{g} \mathrm{plant}^{-1}\right)$, total dry mass $\left(\mathrm{g} \mathrm{plant}^{-1}\right)$, harvest index $(\mathrm{HI})$, transpiration efficiency $\left(\mathrm{TE}, \mathrm{g} \mathrm{kg}^{-1}\right)$ and panicle harvest index (PNHI, i.e. the ratio of the grain weight by the panicle weight)

WW, Well-watered; DS, drought stress

\begin{tabular}{|c|c|c|c|c|c|c|c|c|c|c|c|c|c|}
\hline & \multicolumn{2}{|c|}{$50 \% \mathrm{Fl}$} & \multicolumn{2}{|c|}{ Grain yield } & \multicolumn{2}{|c|}{ Total DW } & \multicolumn{2}{|c|}{$\mathrm{HI}$} & \multicolumn{2}{|c|}{ TE } & \multicolumn{2}{|c|}{ PNHI } \\
\hline & & WW & DS & WW & DS & WW & DS & WW & DS & WW & DS & WW & DS \\
\hline \multicolumn{2}{|l|}{ Mean } & 57 & 56 & 41.97 & 20.59 & 126.94 & 67.05 & 0.33 & 0.27 & 4.38 & 4.82 & 0.75 & 0.70 \\
\hline \multicolumn{2}{|l|}{ Min. } & 46 & 44 & 2.06 & 0.23 & 34.01 & 41.75 & 0.02 & 0.00 & 2.95 & 3.21 & 0.26 & 0.00 \\
\hline \multicolumn{2}{|l|}{$\sigma_{\mathrm{g}}^{2}$} & 13.1 & 17.6 & 166.0 & 38.69 & 664.6 & 43.47 & 0.06173 & 0.00584 & 0.162 & 0.162 & 0.005493 & 0.00623 \\
\hline \multicolumn{2}{|l|}{ s.e. } & 1.9 & 2.3 & 28.2 & 6.53 & 106.3 & 8.89 & 0.00098 & 0.00095 & 0.054 & 0.038 & 0.00099 & 0.00118 \\
\hline \multicolumn{2}{|l|}{ s.e.d. } & 2.14 & 2.02 & 10.07 & 4.80 & 18.83 & 5.99 & 0.057 & 0.056 & 0.45 & 0.39 & 0.061 & 0.067 \\
\hline $\mathrm{G}$ & s.e. & \multicolumn{2}{|c|}{1.94} & \multicolumn{2}{|c|}{12.5} & \multicolumn{2}{|c|}{40.7} & \multicolumn{2}{|c|}{0.00080} & \multicolumn{2}{|c|}{0.032} & \multicolumn{2}{|c|}{0.000942} \\
\hline \multirow[t]{2}{*}{$\mathrm{T}$} & Wald & \multicolumn{2}{|c|}{14.6} & \multicolumn{2}{|c|}{325} & \multicolumn{2}{|c|}{731.6} & \multicolumn{2}{|c|}{56.5} & \multicolumn{2}{|c|}{78.4} & \multicolumn{2}{|c|}{33.1} \\
\hline & Prob. & \multicolumn{2}{|c|}{0.001} & \multicolumn{2}{|c|}{0.001} & \multicolumn{2}{|c|}{0.001} & & & & & & \\
\hline $\mathrm{G} \times \mathrm{T}$ & $\sigma_{\mathrm{gxT}}^{2}$ & & & & & 236 & & & 1342 & & 49 & & 1065 \\
\hline & s.e. & & 42 & & & 43 & & & 0433 & & 32 & & 540 \\
\hline
\end{tabular}


difference between the minimum and the maximum value, whereas under WW conditions these differences were about 4-fold. This reflects in part genotypic differences in plant size and tillering, which became larger under WW conditions. Since the genotypes were randomised in the different replications, it is also a possibility that dwarf germplasm may have suffered from shading from tall germplasm in the WW conditions. This possibility is, however, quite unlikely under DS conditions, where the range of total biomass was smaller than under WW conditions, and also where total biomass differences also reflected large differences in grain yield.

\section{Total water extraction}

Total water extracted under DS conditions varied significantly $(P<0.001)$ among the 149 entries, ranging from 10600 to $15200 \mathrm{~g} \mathrm{plant}^{-1}$ (Table 2). Noticeably, a low coefficient of variation of only $6 \%$ was obtained for the total water extraction in the lysimetric system. Under fully irrigated conditions, the water extracted by the plants also varied significantly, ranging from 10500 to $42300 \mathrm{~g} \mathrm{plant}^{-1}$. Besides an expected treatment effect, the total water extracted showed a large $\mathrm{G} \times \mathrm{T}$ interaction effect, whereas the genotypic effect was non-significant. In fact, the water extracted under WW and DS conditions showed a poor relationship $\left(R^{2}=0.08\right)$. Total water uptake under DS conditions was assessed for each individual race. The Durra race had the highest total water uptake (14 120 g plant $^{-1}, n=20$ ) (Fig. 2). The Durra-Caudatum race had, on average, the lowest total water uptake (13 570 g plant $^{-1}, n=12$ ), followed by the Caudatum-Bicolor accessions (13 800 g plant $\left.^{-1}, n=14\right)$.

The first two water-use measurements for the 31-45 DAS and 45-59 DAS time intervals were similar in WW and DS plants (Fig. 3), although there was a significant, but minor, treatment effect on the water extraction in the 45-59 DAS interval (Table 2). Indeed, the water used under DS in the 45-59 DAS period was above $70 \%$ of that under WW conditions, except for 18 lines where water used was $50-70 \%$ of that under WW. This indicated that for the 29 days following the last irrigation in the

Table 2. Trial means, range of expected means, genetic variance estimate and standard error of estimate, standard error of differences (s.e.d) within treatment, and Wald statistics and $F$-probability for genotype effect, treatment effect and genotype-by-treatment $(G \times T)$ interaction related

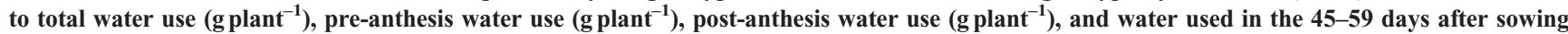

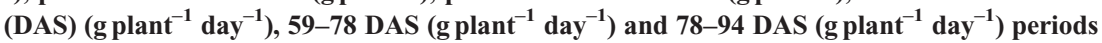

\begin{tabular}{|c|c|c|c|c|c|c|c|c|c|c|c|c|c|}
\hline \multicolumn{2}{|c|}{ Water use } & \multicolumn{2}{|c|}{ Total } & \multicolumn{2}{|c|}{ Pre-anthesis } & \multicolumn{2}{|c|}{ Post-anthesis } & \multicolumn{2}{|c|}{ 45-59 DAS } & \multicolumn{2}{|c|}{$59-78$ DAS } & \multicolumn{2}{|c|}{ 78-94 DAS } \\
\hline \multicolumn{2}{|l|}{ Mean } & 28856 & 13908 & 9383 & 8956 & 20727 & 6452 & 358 & 344 & 401 & 180 & 368 & 112 \\
\hline \multicolumn{2}{|l|}{ Min. } & 10500 & 10620 & 5406 & 4493 & 5854 & 2439 & 141 & 162 & 114 & 70 & 99 & 58 \\
\hline \multicolumn{2}{|l|}{ Max. } & 42320 & 15240 & 15493 & 13628 & 35018 & 10917 & 556 & 668 & 598 & 279 & 630 & 229 \\
\hline \multicolumn{2}{|l|}{$\sigma_{\mathrm{g}}^{2}$} & 27908726 & 158959 & 3641052 & 1731958 & 22464015 & 1982010 & 4528 & 1452 & 4482 & 677 & 7954 & 334 \\
\hline \multicolumn{2}{|l|}{ s.e. } & 4141939 & 50275 & 535809 & 285982 & 3435089 & 301436 & 759 & 969 & 838 & 260 & 1164 & 76.7 \\
\hline \multicolumn{2}{|l|}{ s.e.d. } & 3467 & 436 & 1147 & 999 & 3053 & 961 & 52 & 49 & 57 & 30 & 57 & 18 \\
\hline \multirow[t]{2}{*}{ G } & $\sigma_{\mathrm{g}}^{2}$ & \multicolumn{2}{|c|}{1124515} & \multicolumn{2}{|c|}{2183060} & \multicolumn{2}{|c|}{1452707} & \multicolumn{2}{|c|}{2641} & \multicolumn{2}{|c|}{974} & \multicolumn{2}{|c|}{75} \\
\hline & s.e. & \multicolumn{2}{|c|}{1456941} & \multicolumn{2}{|c|}{328263} & \multicolumn{2}{|c|}{1238507} & \multicolumn{2}{|c|}{600} & \multicolumn{2}{|c|}{375} & \multicolumn{2}{|c|}{430} \\
\hline \multirow[t]{2}{*}{$\mathrm{T}$} & Wald & \multicolumn{2}{|c|}{1017} & \multicolumn{2}{|c|}{8.95} & \multicolumn{2}{|c|}{1132} & \multicolumn{2}{|c|}{4.19} & \multicolumn{2}{|c|}{702} & \multicolumn{2}{|c|}{953} \\
\hline & Prob. & \multicolumn{2}{|c|}{0.001} & \multicolumn{2}{|c|}{0.003} & & 001 & & & & & & \\
\hline $\mathrm{G} \times \mathrm{T}$ & $\sigma_{\mathrm{gxT}}^{2}$ & 1281 & & & 709 & 1048 & 093 & & & & & & \\
\hline & s.e. & 193 & & 14 & 457 & $15^{\circ}$ & 411 & & & & & & \\
\hline
\end{tabular}

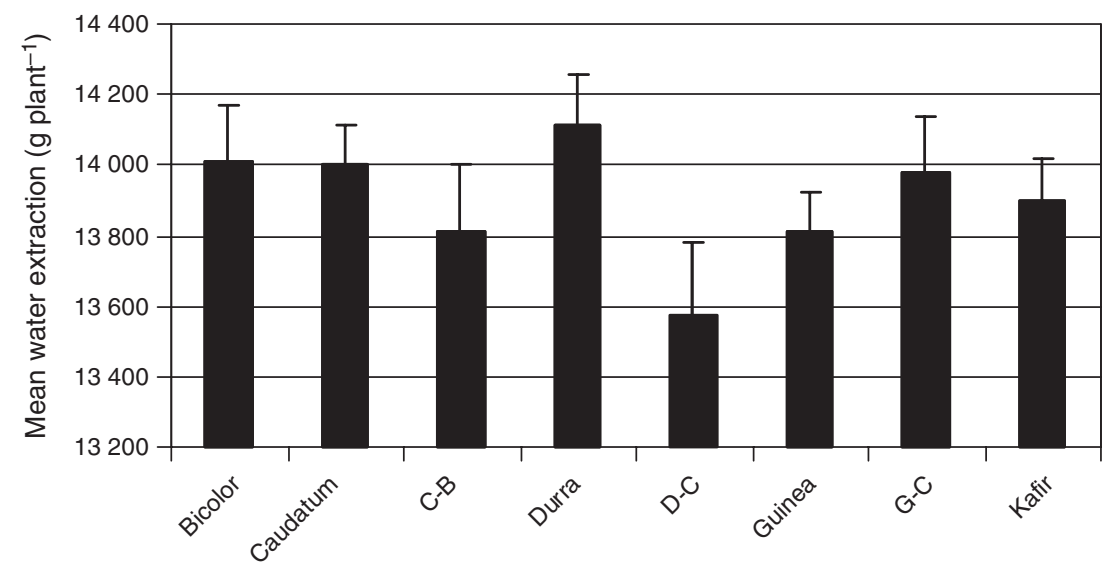

Fig. 2. Total water extracted from the lysimeter soil profile $\left(\mathrm{g} \mathrm{plant}^{-1}\right)$ under terminal water stress conditions in the different sorghum races. Data are the mean of the average transpiration values within each race [Bicolor, $n=17$; Caudatum, $n=31$; Caudatum-Bicolor (C-B), $n=14$; Durra, $n=18$; DurraCaudatum (D-C), $n=13$; Guinea, $n=14$; Guinea-Caudatum (G-C), $n=24$; Kafir, $n=6$ ]. 


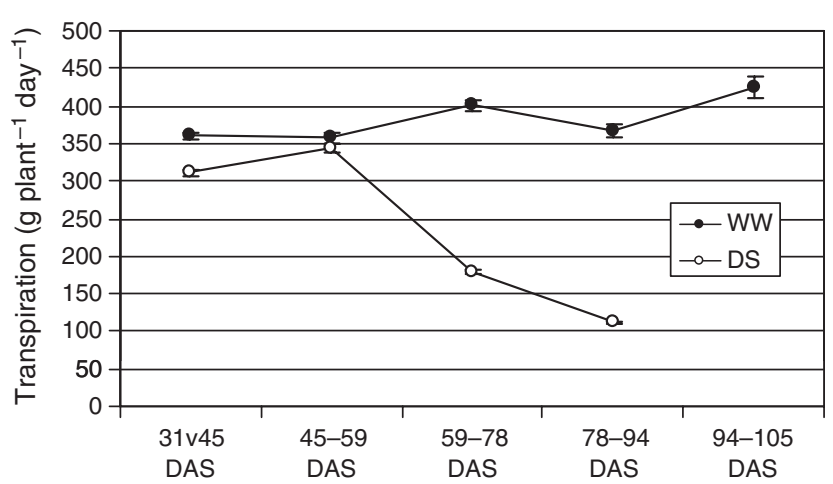

Fig. 3. Profile of transpiration ( $\mathrm{g} \mathrm{plant}^{-1}$ ) as a function of time after sowing. Last irrigation was applied at 30 days after sowing (DAS) in plants exposed to terminal water stress (DS, open symbols) and well watered conditions (WW, closed symbols). Data are the mean ( \pm s.e.) of the average transpiration values for 152 germplasm entries. For the DS and WW plants, five and six lysimeter weighings, respectively, were done, giving four and five transpiration intervals.

DS treatment, DS plants extracted similar amounts of water to WW plants. Water uptake in the 59-78 DAS interval showed a large treatment effect on water extraction, and large and significant genotype and $\mathrm{G} \times \mathrm{T}$ effects, the latter being more important than the genotype effect. Water uptake in the 78-94 DAS interval also showed large treatment and $\mathrm{G} \times \mathrm{T}$ effects, and no significant genotype effect. By 59 DAS, 125 out of 152 entries had flowered and all the others flowered by 65 DAS.

Summarising, the large variation in water extraction capacity under DS conditions, with a tendency to have higher water extraction in the Durra race than in the Durra-Caudatum race, resulted from specific adaptation of genotypes to the stress conditions, and the temporal pattern of water use indicated that stress occurred after flowering for most lines.

\section{Relationships between water extracted before and after anthesis}

The pre-anthesis water use varied by $9 \mathrm{Lplant}^{-1}$ among genotypes (5-14 $\mathrm{L} \mathrm{plant}^{-1}$ range). These differences were, in part, explained by the flowering time $\left(R^{2}=0.70\right.$, data not shown) although large variations in pre-anthesis water use per day, which removes the differences due to flowering time, remained (101-205 g water per day). Pre-anthesis water use was also significantly correlated with the leaf area at anthesis $\left(R^{2}=0.18\right.$, data not shown). Pre-anthesis water use under DS was also predominantly determined by genetic effects (Table 2). The post-anthesis water used ranged from $\sim 2$ to $10 \mathrm{~L}$ plant $^{-1}$ among genotypes. Post-anthesis water use under DS was correlated with flowering time $\left(R^{2}=0.73\right)$ but not to the post-anthesis water use of WW plants. Pre- and post-anthesis water use showed a close negative correlation $\left(R^{2}=0.83\right)$ (Fig. 4). Post-anthesis water use was also predominantly determined by $\mathrm{G} \times \mathrm{T}$ interaction effects, whereas the genotype effects were not significant (Table 2). Post-anthesis water use was also negatively correlated with the leaf area at anthesis $\left(R^{2}=0.17\right)$. These data indicate that despite flowering time determining about two-thirds of the variation in pre- and post-anthesis water use, there was still a

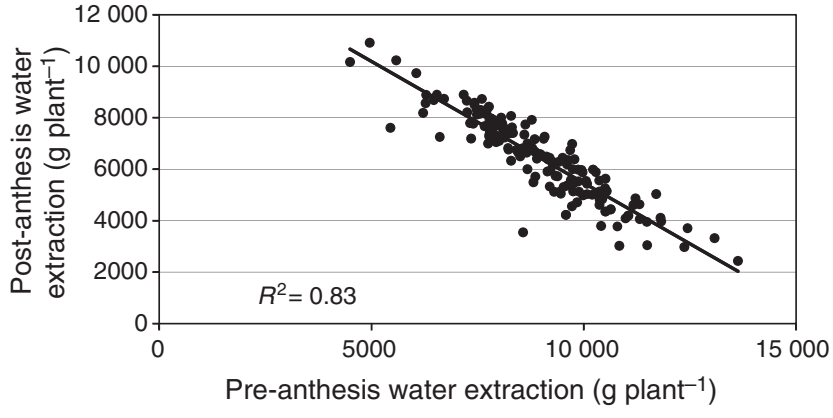

Fig. 4. Relationship between the pre-anthesis water use $\left(\mathrm{g} \mathrm{plant}^{-1}\right)$ and the post-anthesis water use $\left(\mathrm{g} \mathrm{plant}^{-1}\right)$ in 152 germplasm entries. Data are the mean of three replicated lysimeter-grown plants per genotype.

large range of variation in pre- and post-anthesis water use at any level of flowering time.

\section{Transpiration efficiency}

Transpiration efficiency varied largely among entries, ranging from 3.21 to $6.09 \mathrm{~g} \mathrm{~kg}^{-1}$ water transpired under DS conditions. The coefficient of variation was only $13.6 \%$. Under fully irrigated conditions, TE also varied significantly, ranging from 2.95 and $5.59 \mathrm{~g} \mathrm{~kg}^{-1}$ (Table 1). The grand mean of $4.30 \mathrm{~g} \mathrm{~kg}^{-1}$ was lower than under DS conditions $\left(4.82 \mathrm{~g} \mathrm{~kg}^{-1}\right)$. TE under DS and WW conditions were correlated but the correlation coefficient was weak $\left(R^{2}=0.13\right.$, data not shown). Besides a strong treatment effect on TE, genotype and $\mathrm{G} \times \mathrm{T}$ interaction effects were both significant although the magnitude of the $\mathrm{G}$ effects was slightly higher. Transpiration efficiency was assessed for each individual race under DS conditions. The Guinea race exhibited the lowest mean TE values $\left(4.29 \mathrm{~g} \mathrm{~kg}^{-1}, n=13\right)$, followed by the Kafir (4.58 $\left.\mathrm{g} \mathrm{kg}^{-1}, n=6\right)$, whereas the Guinea-Caudatum, Durra and Caudatum races had the highest mean TE values $(5.09,5.05$ and $4.98 \mathrm{~g} \mathrm{~kg}^{-1}, n=25,20$ and 32, respectively) (Fig. 5). In summary, TE was mostly driven by genotypic effects rather than by $\mathrm{G} \times \mathrm{T}$ interactions, and high $\mathrm{TE}$ variants were identified, especially in the Guinea-Caudatum, Durra and Caudatum races.

\section{Relationships between water extraction, TE, HI, and yield}

Regression analyses were conducted between grain yield and water used, TE, and HI. The relationship between grain yield and water used was significant under fully irrigated conditions only $\left(R^{2}=0.33\right)$, but not under DS conditions (data not shown). Similarly, grain yield was significantly related to TE under WW conditions $\left(R^{2}=0.35\right)$ and, although the relationship was significant under DS conditions, the correlation coefficient was weak $\left(R^{2}=0.07\right)$ (data not shown).

Therefore, individually, neither the total water used nor TE had any substantial bearing on yield under DS conditions. This was because the relationship between yield and $\mathrm{HI}$ was highly significant, and more so under DS conditions $\left(R^{2}=0.88\right)$ than under WW conditions $\left(R^{2}=0.53\right)$ (Fig. $\left.6 a\right)$. However, for any given $\mathrm{HI}$ level, Fig. $6 a$ indicates clearly that substantial variation in yield remained unexplained by HI, especially at HI levels above 0.30 . These residual yield variations unexplained by $\mathrm{HI}$ were calculated by subtracting the yield predicted by the 


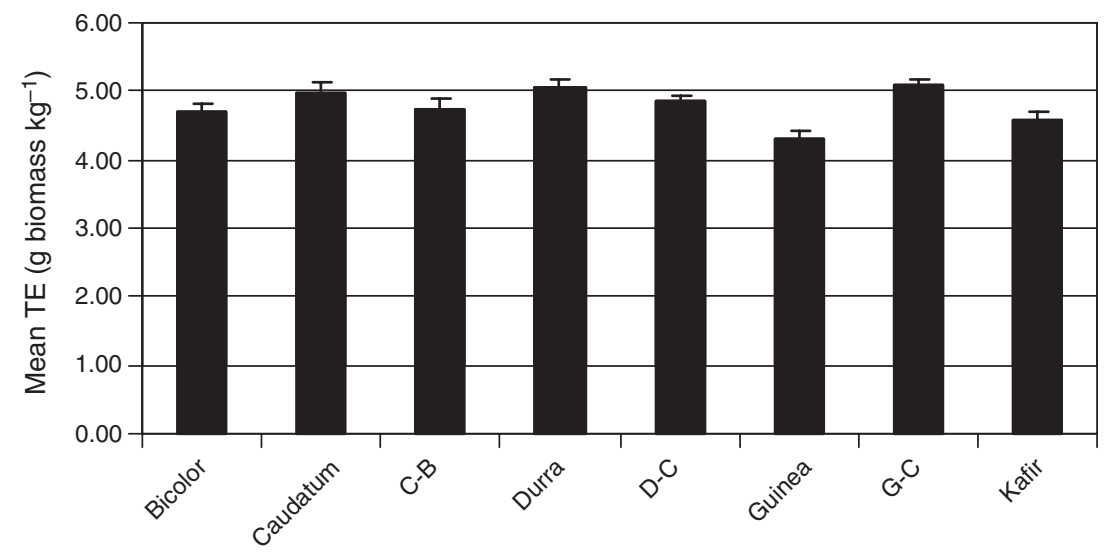

Fig. 5. Transpiration efficiency $\left(\mathrm{g} \mathrm{kg}^{-1}\right.$ water transpired) under terminal water stress conditions in the different sorghum races. Data are the mean of the average transpiration values within each race [Bicolor, $n=17$; Caudatum, $n=31$; Caudatum-Bicolor (C-B), $n=14$; Durra, $n=18$; Durra-Caudatum (D-C), $n=13$; Guinea, $n=14$; Guinea-Caudatum (G-C), $n=24$; Kafir, $n=6$ ].
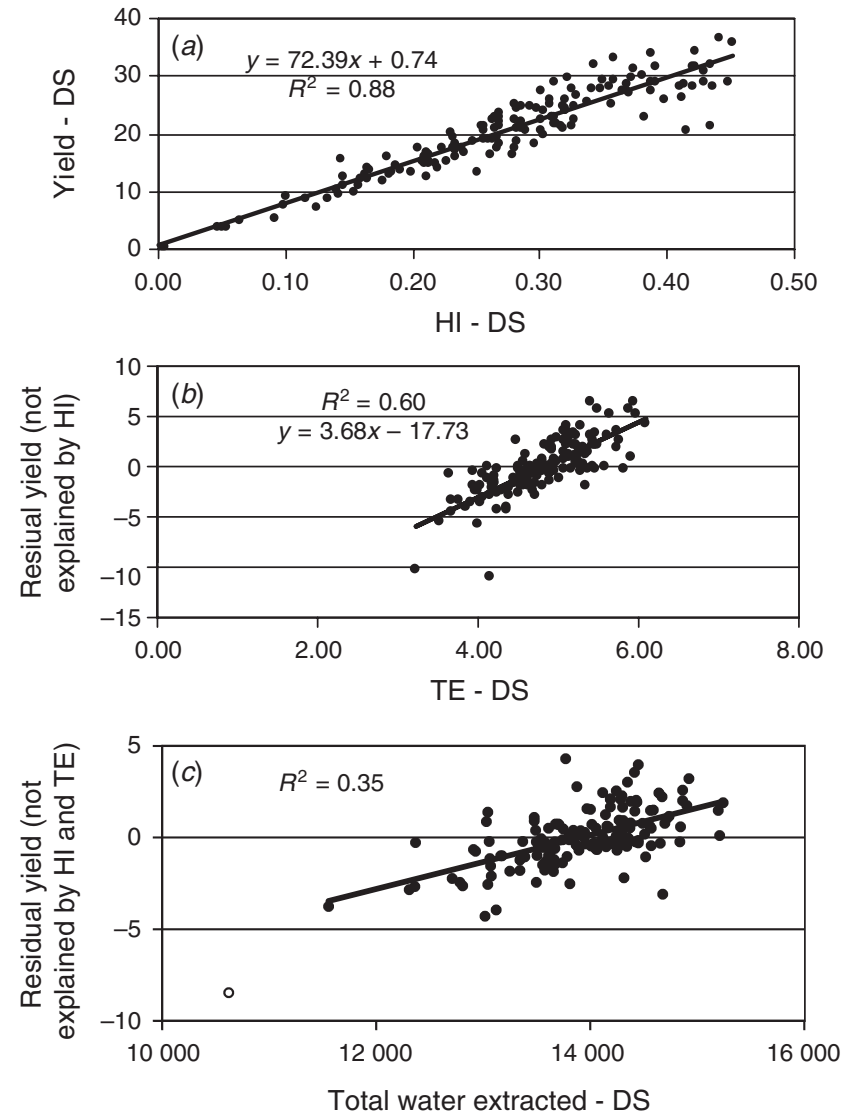

Fig. 6. Relationship between ( $a$ ) seed yield under terminal water stress and the harvest index $(\mathrm{HI}),(b)$ relationship between the residual yield variations unexplained by $\mathrm{HI}$ and transpiration efficiency (TE), and (c) relationship between the residual yield variations unexplained by either $\mathrm{HI}$ or TE and the total water extracted from the soil profile in 152 germplasm entries. Data are the mean of three replicated lysimeter-grown plants per genotype. regression equation (Fig. $6 a$ ) from the observed yields, following Vadez et al. (2007b). These residuals showed a highly significant correlation with TE $\left(R^{2}=0.60\right)$ (Fig. $\left.6 b\right)$ and the total water extracted $\left(R^{2}=0.40\right.$; data not shown). Similarly, for any given TE level, yield variation remained unexplained by $\mathrm{HI}$ and TE. These residual yields were calculated in a similar way, using the regression equation of Fig. $6 b$. These residual yields, unexplained by either the HI or TE, were closely related to the total water used $\left(R^{2}=0.43\right.$ or 0.35 , excluding or including an outlier data point on the left of the regression curve) (Fig. 6c). Other regressions were tested between these residuals and the pre- and post-anthesis water use, and the preand post-anthesis water used normalised by the flowering time, but no significant relationships were found (data not shown).

Similar results were observed from a multilinear regression, where an additive model was used (Table 3), among several others that were tested. The model explained $98 \%$ of the phenotypic variation in yield. In that analysis, HI was the

Table 3. Multilinear regression between yield and several explanatory variables under DS conditions: harvest index, transpiration efficiency, total water extracted, post-anthesis water use, water used in the 45-59 days after sowing (DAS) and 59-78 DAS periods, and days to flowering

n.s., not significant

\begin{tabular}{lclcc}
\hline Factors & Coefficient & s.e. & $t$-value & $P>t$ \\
\hline Harvest index & 67.6 & 0.77 & 87.73 & 0.000 \\
Transpiration efficiency & 4.28 & 0.14 & 29.59 & 0.000 \\
Total water extracted & 0.00163 & 0.00015 & 10.90 & 0.000 \\
Post-anthesis water use & -0.00038 & 0.00017 & -2.30 & 0.023 \\
Water use between & 0.00011 & 0.00015 & 1.81 & n.s. \\
$\quad$ 45-59 DAS & & & & \\
Water use between & 0.00045 & 0.00019 & 2.32 & 0.021 \\
$\quad$ 59-78 DAS & & & & \\
$\quad \begin{array}{l}\text { Days to 50\% flowering } \\
\text { Constant }\end{array}$ & -0.161 & 0.053 & -3.02 & 0.003 \\
\hline
\end{tabular}


explanatory variable accounting for the largest component of yield, followed by TE and water used. In this model, the postanthesis water use had a significant negative effect on yield, while the water extracted in the 59-78 DAS period, corresponding to the flowering stage of most genotypes, had a significant positive effect on yield. Finally, the time to flowering had a significant negative effect on grain yield (Table 3). The same approach was used to explain the residual yield variations not explained by HI. The best model explained $79 \%$ of the variation in the residuals and parameters having the most influence were TE and the total water use, with TE having a probability coefficient about twice that of total water use (Table 4). In that model, the water extracted in the 45-59 DAS and 59-78 DAS intervals were both significantly and positively related to the residual yield variations.

In summary, besides a strong HI effect on yield under DS conditions, the large yield variations remaining unexplained by HI were mostly driven by TE, and then next by total water extraction differences.

\section{Discussion}

Our data showed a 2-fold range of variation for TE and almost $20 \%$ variation for water extraction $\left(3 \mathrm{~L} \mathrm{plant}^{-1}\right.$, equivalent to $30 \mathrm{~mm}$ on a field basis) under water stress in this selection of lines from the sorghum reference collection. Water extraction and TE measurements in the lysimeters were reliable, exhibiting very low coefficients of variation (6 and 13.6\%, respectively). After removing the proportion of yield differences explained by HI, there was still a substantial yield variation unexplained, and this was highly significantly related to TE. Water extraction only ranked third when accounting for yield variations unexplained by either $\mathrm{HI}$ or TE. High genetic variation for TE and water extraction offer substantial breeding opportunities, with high TE and water extraction variants in the Durra race being a critical source of key terminal drought adaptation traits for sorghum. Importantly, high TE and water extraction are not necessarily mutually exclusive, as evidenced by variants of the Durra race.

\section{Large genotypic differences in TE}

Transpiration efficiency was increased by $\sim 10 \%$ under DS compared with WW conditions and since the $\mathrm{G} \times \mathrm{T}$

Table 4. Multilinear regression between the residual yield variations not explained by harvest index and several explanatory variables under DS conditions: transpiration efficiency, total water extracted, postanthesis water use, water used in the 45-59 days after sowing (DAS) and 59-78 DAS periods, and days to flowering n.s., not significant

\begin{tabular}{lclrc}
\hline Factors & Coefficient & s.e. & $t$-value & $P>t$ \\
\hline Transpiration efficiency & 3.44 & 0.18 & 18.49 & 0.000 \\
Total water extracted & 0.00147 & 0.00019 & 7.77 & 0.000 \\
Post-anthesis water use & -0.00044 & 0.00022 & -2.02 & 0.046 \\
Water use between & 0.00029 & 0.00012 & 2.39 & 0.018 \\
$\quad$ 45-59 DAS & & & & \\
$\quad$ Water use between & 0.00066 & 0.00025 & 2.64 & 0.009 \\
$\quad$ 59-78 DAS & & & & \\
$\begin{array}{l}\text { Days to 50\% flowering } \\
\text { Constant }\end{array}$ & -0.105 & 0.069 & -1.53 & n.s. \\
\hline
\end{tabular}

interactions were rather small, differences were driven by genotypic effects. This contrasted with previous results reporting a higher TE under fully irrigated conditions (Donatelli et al. 1992). Also the range of variation reported here under both water regimes was almost 2-fold higher than in previous work reporting 20\% (Donatelli et al. 1992) and 25\% (Hammer et al. 1997) differences in TE. The values reported here were slightly below the range found by Balota et al. (2008) (5.04-7.55 $\mathrm{g} \mathrm{kg}^{-1}$ water), which is the only reported study where TE was measured over the entire crop cycle. The values here were also slightly below that in Hammer et al. (1997) $\left(6.0-7.7 \mathrm{~g} \mathrm{~kg}^{-1}\right)$. Many of these differences could simply be related to differences in vapour pressure deficit (VPD) under different conditions. Also roots were not included in our TE assessment (inclusion of roots could increase absolute TE values by $\sim 30-40 \%$ ). There was no significant relationship between TE and total water extraction, which could be used as a proxy for root mass. This led us to conclude that the non-inclusion of root mass in our TE calculation was unlikely to undermine much of the genetic differences in TE explained here.

In the current work, TE was highly correlated with total biomass $\left(R^{2}=0.82\right.$, data not shown), which is similar to that found recently by Xin et al. (2009), but different from Hammer et al. (1997). Also, the absence of relationship between TE and total water use, tested here in a large and representative set of germplasm, undermines previous speculation that TE and water use could be negatively related (Blum 2005) and clearly shows that it is possible to find germplasm capable of exhibiting both high water extraction and high TE, as previously shown (Peng and Krieg 1992). Indeed, both high water extraction and high TE were exhibited by variants of the Durra race in this study. When comparing races, it appeared that both Caudatum and Durra had overall higher values of TE than other landraces. Therefore, large genotypic variation for TE, especially in Caudatum and Durra races, could be exploited by sorghum breeding programs. The reason for the superiority of the Caudatum and Durra races is unknown but we speculate that some could be in the environmental conditions in which these landraces have evolved. It has been recently shown that certain sorghum genotypes restrict transpiration at high vapour pressure deficit (Gholipoor et al. 2010), which could lead to water saving and/or differences in TE.

\section{Large differences in water extraction capacity}

Little work has been done to assess water extraction per se, except for a detailed study on two genotypes by Robertson et al. (1993). Indeed, most studies in different crops so far have relied on assessing rooting characteristics and not on the function of root systems (Siddique et al. 1990; Sanguineti et al. 1998; Kashiwagi et al. 2005). Therefore, our study may be the first to report a large range in variation for water extraction across an extensive germplasm set. Because of the lack of a strong relationship between water use under WW and DS conditions, water extraction differences were not related to constitutive traits but rather to differences in a response to stress. The low coefficient of variation $(6 \%)$ for total water extraction measurements clearly indicates the value of the lysimetric system for assessing water extraction. In addition, it resolves previous 
complications related to identifying drought-adaptive rooting traits (Price et al. 2002).

These water extraction differences could relate to either a deeper rooting (Singh et al. 2010), or to differences in the effective depth of water extraction. We estimate that each cylinder contains a total of $27 \mathrm{~L}$ of water $(\sim 23 \% \mathrm{w} / \mathrm{w}$ is a typical value for this Alfisol), from which $\sim 70 \%$ can be extracted for transpiration . Therefore, $\sim 19 \mathrm{~L}$ of water would then be available for extraction from the soil profile of the lysimeters, assuming the root length density was sufficient to do so. Hence, the sorghum genotypes extracting the most water from the profile, i.e. $\sim 13 \mathrm{~L}$ after deducting $2 \mathrm{~L}$ of water that were added in the course of the experiment, had roots sufficient to extract all possible water from $\sim 70 \%$ of the soil profile. By contrast, genotypes extracting the least water would have attained full extraction to only $~ 50 \%$ of the soil profile. For the sake of representing these water extraction differences in terms of rooting depth, a 3-L plant ${ }^{-1}$ difference represents all the water available in a $40-\mathrm{cm}$ depth of the lysimeter soil profile.

Our method of assessing the pattern of water extraction during the whole life cycle is an innovation that adds precision and high throughput to existing field-based equipments (e.g. time-domain reflectometry (TDR), neutron probes). Rather than relying on static and destructive measurements of rooting characteristics, lysimeters sown with individual plants enabled water use to be evaluated under controlled water regimes in a dynamic manner. It revealed a large range of variation in both pre- and post-anthesis water use, and that these two parameters were highly and negatively correlated. Although both pre- and post-anthesis water use were related to flowering time, Fig. 4 also clearly shows that for a similar level of pre-anthesis water use, there was still variation in post-anthesis water use, indicating that genotypes varied in their capacity to extract water during the grain-filling period. More work is needed to assess how post-anthesis water use affects yield in genotypes with similar flowering time and preanthesis water use, as previously considered (Hammer 2006). The profile of water extraction also provided insight into when sorghum plants are getting stressed, i.e. not until $\sim 4$ weeks after the last irrigation. Although this type of information has been acquired from the field (Ritchie 1981; Steiner 1986; Turner et al. 1986), it is possible to acquire at a much larger scale and with more precision using the lysimetric system, enabling detailed studies of the relationships between patterns of water use and grain yield.

\section{Besides $\mathrm{HI}$, yield relates closely to TE and third only to water use}

Yield variations under DS had no relation with the yield potential (Fig. 1). With a crop density of 11 plant $\mathrm{m}^{-2}$ in the lysimetric system, the mean trial grain yield under terminal stress corresponded to $2.1 \mathrm{t} \mathrm{ha}^{-1}$, which was in the range of yield previously observed in the field with post-rainy sorghum materials of 1.2-2.1 $\mathrm{t} \mathrm{ha}^{-1}$ under similar weather conditions (Mahalakshmi and Bidinger 2002). Yields under fully irrigated conditions corresponded to $4.2 \mathrm{t} \mathrm{ha}^{-1}$, indicating that the stress imposed in the cylinders was within the desired range.

Among the components of Passioura's equation, HI explained the largest portion of the genetic variation in yield.
This would be expected from germplasm with such a large range of variation for $\mathrm{HI}$ under both water regimes, and also from the fact that yield and $\mathrm{HI}$ have terms in common. Nevertheless, Fig. 6 also showed that yield variation remained unexplained by HI. Our multilinear approach, using a similar methodology to that in previous work (Bidinger et al. 1987; Vadez et al. 2007b), shows that the effect of HI on the yield variation needs to be removed before the strong effect of TE on the substantial residual variations can be highlighted. This reveals the important impact of TE on yield differences under terminal stress conditions in sorghum, as previously suggested (Hammer et al. 1997; Sinclair et al. 2005; Xin et al. 2009).

Interestingly, under well watered conditions, the $\mathrm{HI}$ had much less of an influence on yield than under terminal stress $\left(R^{2}=0.57\right.$ v. $\left.R^{2}=0.88\right)$. By contrast, both $\mathrm{TE}$ and water used had a significant effect on yield $\left(R^{2}=0.34\right.$ for TE; $R^{2}=0.16$ for water used) when water was not limiting. In that case, we also computed the residual yield unexplained by HI. The correlation between these residuals and TE was also highly significant $\left(R^{2}=0.29, P<0.01\right)$, although it did not improve the direct relationship that was previously found between TE and yield. By contrast, the residuals were highly correlated with the water used $\left(R^{2}=0.69\right)$, with a significant improvement compared with the relationship previously drawn between water used and yield. These data then support the importance of maximising water use when water is non-limiting, as previously suggested (Blum 2005).

These data highlight the potential of the lysimetric system to accurately assess the various components of Passioura's equation, allowing the respective weighting of their importance under different watering regimes. Work is now in progress to test several water deficit conditions to assess the possible change in the bearing of each component. In addition, other traits also had a significant bearing on yield under terminal drought. In particular, extracting more water during the 59-78 DAS time interval, which corresponded to flowering and early grain filling, had a significant and positive effect on yield. This was despite the highly variable germplasm used in this work (germplasm with differences in tillering and HI). These data suggest that water uptake during that period may be critical for successful seed setting and grain filling of the crop, as previously shown and suggested (Vadez et al. 2007a; Ratnakumar et al. 2009; Zaman-Allah et al. 2011), and also found in pearl millet (Vadez et al. 2009).

Summarising, the lysimetric system was suitable for (i) generating yield data that approximate field conditions, and (ii) assessing the value of the various components of the Passioura equation on yield. The use of either stepwise regression or multilinear regression analysis was needed to remove components of greater influence in order to highlight the significant influence of other traits.

\section{Acknowledgements}

Work was funded by a grant from the Australian Centre for International Agriculture Research (ACIAR) (CIM-2007-120) and by a grant by the Generation Challenge Program (G4008.02 - SP1). Authors are thankful to Dr Neil C. Turner for critically reading the manuscript. Authors are grateful for the expert technical help from Mr N. Pentaiah and Mr M. Anjaiah. 


\section{References}

Balota M, Payne WA, Rooney W, Rosenow D (2008) Gas exchange and transpiration ratio in sorghum. Crop Science 48, 2361-2371. doi:10.2135/cropsci2008.01.0051

Bhan S, Singh HG, Singh A (1973) Note on root revelopment as an index of drought resistance in sorghum (Sorghum bicolor L. Moench). Indian Journal of Agricultural Sciences 43, 828-830.

Bidinger FR, Mahalakshmi V, Rao GDP (1987) Assessment of drought resistance in pearl millet [Pennisetum americanum (L.) Lecke]. II: Estimation of genotype response to stress. Australian Journal of Agricultural Research 38, 37-48. doi:10.1071/AR9870037

Blum A (2005) Drought resistance, water use efficiency, and yield potential - are they compatible, dissonant, or mutually exclusive. Australian Journal of Agricultural Research 56, 1159-1168. doi:10.1071/AR05069

Blum A, Jordan WR, Arkin GF (1977) Sorghum root morphogenesis and growth. II. Manifestation of heterosis. Crop Science 17, 153-157. doi:10.2135/cropsci1977.0011183X001700010040x

Crasta OR, Xu WW, Rosenow DT, Mullet J, Nguyen HT (1999) Mapping of post-flowering drought resistance traits in grain sorghum: association between QTLs influencing premature senescence and maturity. Molecular \& General Genetics 262, 579-588. doi:10.1007/s004380051120

Donatelli M, Hammer GL, Vanderlip RL (1992) Genotype and water limitation effects on phenology, growth, and transpiration efficiency in grain sorghum. Crop Science 32, 781-786. doi:10.2135/cropsci1992.001 1183X003200030041x

Gholipoor M, Prasad PVV, Mutava RN, Sinclair TR (2010) Genetic variability of transpiration response to vapor pressure deficit among sorghum genotypes. Field Crops Research 119, 85-90.

Hammer GL (2006) Pathways to prosperity: breaking the yield barrier in sorghum. Agricultural Science 19, 16-22.

Hammer GL, Farquhar GD, Broad IJ (1997) On the extent of genetic variation for transpiration efficiency in sorghum. Australian Journal of Agricultural Research 48, 649-655. doi:10.1071/A96111

Harris K, Subudhi PK, Borrell AK, Jordan DB, Rosenow D, Nguyen H, Klein P, Klein R, Mullet J (2006) Sorghum stay-green QTL individually reduce post-flowering drought-induced leaf senescence. Journal of Experimental Botany 58, 327-338. doi:10.1093/jxb/erl225

Hubick KT, Farquhar GD, Shorter R (1986) Correlation between water-use efficiency and carbon isotope discrimination in diverse peanut (Arachis) germplasm. Australian Journal of Plant Physiology 13, 803-816. doi:10.1071/PP9860803

Jordan WR, Miller FR, Morris DE (1979) Genetic variation in root and shoot growth of sorghum in hydroponics. Crop Science 19, 468-472. doi:10.2135/cropsci1979.0011183X001900040010x

Kashiwagi J, Krishnamurthy L, Upadhyaya HD, Krishna H, Chandra S, Vadez V, Serraj R (2005) Genetic variability of drought-avoidance root traits in the mini-core germplasm collection of chickpea (Cicer arietinum L.). Euphytica 146, 213-222. doi:10.1007/s10681-0059007-1

Kholová J, Hash CT, Kočvá M, Vadez V (2010a) Constitutive water conserving mechanisms are correlated with the terminal drought tolerance of pearl millet (Pennisetum americanum L.). Journal of Experimental Botany 61, 369-377. doi:10.1093/jxb/erp314

Kholová J, Hash CT, Kumar LK, Yadav RS, Kočvá M, Vadez V (2010b) Terminal drought tolerant pearl millet [Pennisetum glaucum (L.) R. Br.] have high leaf $\mathrm{ABA}$ and limit transpiration at high vapor pressure deficit. Journal of Experimental Botany 61, 1431-1440. doi:10.1093/ jxb/erq013

Kirkegaard JA, Lilley JM, Howe GN, Graham JM (2007) Impact of subsoil water use on wheat yield. Australian Journal of Agricultural Research 58, 303-315. doi:10.1071/AR06285
Krishnamurthy L, Vadez V, Devi MJ, Serraj R, Nigam SN, Sheshshayee MS, Chandra S, Aruna R (2007) Variation in transpiration efficiency and its related traits in a groundnut (Arachis hypogaea L.) mapping population. Field Crops Research 103, 189-197. doi:10.1016/j.fcr. 2007.06.009

Mahalakshmi V, Bidinger FR (2002) Evaluation of stay-green sorghum germplasm lines at ICRISAT. Crop Science 42, 965-974. doi:10.2135/ cropsci2002.0965

Manschadi AM, Christopher JT, Peter deVoil P, Hammer GL (2006) The role of root architectural traits in adaptation of wheat to water-limited environments. Functional Plant Biology 33, 823-837. doi:10.1071/ FP06055

Mayaki WC, Stone LR, Teare ID (1976) Irrigated and nonirrigated soybean, corn, and grain sorghum root systems. Agronomy Journal 68, 532-534. doi:10.2134/agronj1976.00021962006800030028x

Nageswara Rao RC, Talwar HS, Wright GC (2001) Rapid assessment of specific leaf area and leaf nitrogen in peanut (Arachis hypogaea L.) using a chlorophyll meter. Journal of Agronomy \& Crop Science 186, 175-182. doi:10.1046/j.1439-037X.2001.00472.x

Passioura JB (1977) Grain yield, harvest index and water use of wheat. Journal of Australian Institute of Agriculture Science 43, 117-121.

Peng S, Krieg DR (1992) Gas exchange traits and their relationship to water use efficiency. Crop Science 32, 386-391. doi:10.2135/cropsci 1992.0011183X003200020022x

Price AH, Townend J, Jones MP, Audebert A, Courtois B (2002) Mapping QTLs associated with drought avoidance in upland rice grown in the Philippines and West Africa. Plant Molecular Biology 48, 683-695. doi:10.1023/A:1014805625790

Ratnakumar P, Vadez V, Nigam SN, Krishnamurthy L (2009) Assessment of transpiration efficiency in peanut (Arachis hypogaea L.) under drought by lysimetric system. Plant Biology 11, 124-130. doi:10.1111/j.14388677.2009.00260.x

Ritchie JT (1981) Water dynamics in the soil-plant-atmosphere system. Plant and Soil 58, 81-96. doi:10.1007/BF02180050

Robertson MJ, Fukai S, Ludlow MM, Hammer GL (1993) Water extraction by grain sorghum in a subhumid environment. 1. Analysis of the water extraction pattern. Field Crops Research 33, 81-97. doi:10.1016/03784290(93)90095-5

Salih AA, Ali IA, Lux A, Luxova M, Cohen Y, Sugimoto Y, Inanga S (1999) Rooting, water uptake, and xylem structure adaptation to drought of two sorghum cultivars. Crop Science 39, 168-173. doi:10.2135/ cropsci1999.0011183X003900010027x

Sanguineti MC, Giuliani MM, Govi G, Tuberosa R, Landi P (1998) Root and shoot traits of maize inbred lines grown in the field and in hydroponic culture and their relationships with root lodging. Maydica 43, 211-216.

Serraj R, Hash CT, Buhariwalla HK, Bidinger FR, Folkertsma RT, Chandra S, Gaur PM, Kashiwagi J, Nigam SN, Rupakula A, Crouch JH (2005) Marker-assisted breeding for crop drought tolerance at ICRISAT: achievements and prospects. In 'The wake of the double helix: from the green revolution to the gene revolution'. (Eds R Tuberosa, RL Phillips, MD Gale) pp. 217-238. (Avenue Media: Bologna, Italy)

Siddique KHM, Belford RK, Tennant D (1990) Root: shoot of old and modern, tall and semi-dwarf wheat in Mediterranean environment. Plant and Soil 121, 89-98. doi:10.1007/BF00013101

Sinclair TR, Hammer GL, van Oosterom EJ (2005) Potential yield and wateruse efficiency benefits in sorghum from limited maximum transpiration rate. Functional Plant Biology 32, 945-952. doi:10.1071/FP05047

Singh V, van Oosterom EJ, Jordan DR, Messina CD, Cooper M, Hammer GL (2010) Morphological and architectural development of root systems in sorghum and maize. Plant and Soil 333, 287-299. doi:10.1007/s11104010-0343-0 
Steiner JL (1986) Dryland grain sorghum water use, light interception, and growth response to planting geometry. Agronomy Journal 78, 720-726. doi:10.2134/agronj1986.00021962007800040032x

Turner NC, Hearn AB, Begg JE, Constable GA (1986) Cotton (Gossypium hirsutum L.): physiological and morphological responses to water deficits and their relationship to yield. Field Crops Research 14, 153-170. doi:10.1016/0378-4290(86)90054-7

Udayakumar M, Sheshshayee MS, Nataraj KN, Bindu Madhava H, Devendra R, Aftab Hussain IF, Prasad TG (1998) Why has breeding for water-use efficiency not been successful? An analysis and alternate approach to exploit this trait for crop improvement. Current Science 74, 994-1000.

Upadhyaya HD, Pundir RPS, Dwiwedi SL, Gowda CLL, Reddy VG, Singh S (2009) Developing a mini core collection of sorghum for diversified utilization of germplasm. Crop Science 49, 1769-1780. doi:10.2135/ cropsci2009.01.0014

Vadez V, Krishnamurthy L, Gaur PM, Upadhyaya HD, Hoisington DA, Varshney RK, Turner NC, Siddique KHM (2007b) Large variation in salinity tolerance is explained by differences in the sensitivity of reproductive stages in chickpea. Field Crops Research 104, 123-129. doi:10.1016/j.fcr.2007.05.014

Vadez V, Krishnamurthy L, Kashiwagi JW, Kholova J, Devi JM, Sharma KK, Bhatnagar-Mathur P, Hoisington DA, Hash CT, Bidinger FR, Keatinge JDH (2007a) Exploiting the functionality of root systems for dry, saline, and nutrient deficient environments in a changing climate. Journal of SAT Agricultural Research 4(Special Symposium edn). (Available at: www. icrisat.org/journal/specialproject.htm)
Vadez V, Kholová J, Kakkera A, Hash CT, Yadav R, Kočová M (2009) Pearl millet genotypes differing for a terminal drought tolerance QTL contrast for traits related to the control of leaf water loss. In 'Proceedings from the Interdrought III Conference. 11-16 October'. pp.170. (Shanghai Academy of Agriculture Science: Shanghai, China)

Vadez V, Rao S, Kholova J, Krishnamurthy L, Kashiwagi J, Ratnakumar P, Sharma KK, Bhatnagar-Mathur P, Basu PS (2008) Roots research for legume tolerance to drought: Quo vadis? Journal of Food Legumes 21, $77-85$.

Wright GC, Nageswara Rao RC, Farquhar GD (1994) Water-use efficiency and carbon isotope discrimination in peanut under water deficit conditions. Crop Science 34, 92-97. doi:10.2135/cropsci1994. 0011183X003400010016x

Xin Z, Aiken R, Burke JJ (2009) Genetic diversity of transpiration efficiency in sorghum. Field Crops Research 111, 74-80. doi:10.1016/j.fcr.2008. 10.010

Zaman-Allah M, Jenkinson D, Vadez V (2011) A conservative pattern of water use, rather than deep or profuse rooting, is critical for the terminal drought tolerance of chickpea. Journal of Experimental Botany doi:10.1093/jxb/err139

Manuscript received 22 January 2011, accepted 15 July 2011 